\title{
EFEITO DO PESO DE TILÁPIA DO NILO (Oreochromis niloticus) SOBRE O RENDIMENTO E A QUALIDADE DE SEUS FILÉS DEFUMADOS COM E SEM PELE ${ }^{1}$
}

\author{
Maria Luiza Rodrigues de SOUZA $^{2, *}$, Elisabete M. Macedo VIEGAS ${ }^{3}$, \\ Paulo José do Amaral SOBRAL ${ }^{3}$, Sérgio do Nascimento KRONKA 4
}

\begin{abstract}
RESUMO
O objetivo deste estudo foi avaliar o efeito de diferentes pesos de tilápia do Nilo (Oreochromis niloticus), sobre o rendimento e a qualidade dos seus filés com e sem pele, submetidos à defumação, tendo em conta o potencial de industrialização da referida espécie. Foram utilizados 100 exemplares em três classes de peso $(\mathrm{C} 1=500$ a $600 \mathrm{~g}, \mathrm{C} 2=601 \mathrm{a} 700 \mathrm{~g}$ e $\mathrm{C} 3=701 \mathrm{a} 800 \mathrm{~g})$. De cada peixe foram retirados um filé com pele e outro sem pele e submetidos à salmouragem e à defumação a quente. O peso influenciou no rendimento dos filés in natura $(\mathrm{C} 1=38,54 ; \mathrm{C} 2=40,23$ e C3 =40,47\%) e defumado (C1 = 22,97; C2 =24,51 e C3 = 24,68\%), e o indice de Massa de Filé in natura $\left(\mathrm{C} 1=36,69 ; \mathrm{C} 2=39,45\right.$ e C3 $\left.=41,18 \mathrm{~g} \cdot \mathrm{cm}^{-2}\right)$, sendo maior para os peixes das classes $\mathrm{C} 2$ e $\mathrm{C} 3$. Os filés com pele apresentaram maior $(\mathrm{P}<0,05)$ atividade de água $(0,99)$ que os filés sem peles $(0,98)$. Os filés defumados apresentaram teores de sal maiores $(\mathrm{P}<0,01)$ que os in natura, observando-se também niveis mais elevados nos filés sem pele da C1. Não houve diferença na cor dos filés, exceto para a* e b*, no in natura, que foi inferior. Os filés defumados provenientes dos peixes da classe C3 tiveram melhor aceitação sensorial. Houve redução no comprimento, largura, espessura e área dos filés após a defumação. A partir do peso dos peixes (X) da classe C3, foi possivel utilizar a equação $Y=-21,52+0,16034 X(r=0,80)$ para predizer o tamanho dos filés defumados com pele, e $Y=-17,74+0,14198 X(r=0,81)$ para os defumados sem pele. Independentemente da presença ou não da pele, os filés defumados provenientes de peixes maiores (classes C2 e C3) proporcionam melhores resultados quanto ao rendimento (aproximadamente 24\%), assim como na avaliação sensorial, com relação ao teor de sal e aceitação geral. Os filés in natura apresentaram valores inferiores para $a^{*}$ e $b^{*}$. As classes de peso e presença de peles nos filés não influenciaram na composição, porém causaram variações na espessura e área dos mesmos. Os maiores filés obtidos foram os com pele e pertencentes à classe C3.
\end{abstract}

Palavras-chave: Tilápia do Nilo (Oreochromis niloticus); área de filé; índice de massa de filé; avaliação sensorial; composição centesimal; defumação.

\section{SUMMARY}

EFFECT OF NILE TILAPIA (Oreochromis niloticus) WEIGHT ON YIELD AND QUALITY OF THEIR SMOKED AND IN NATURA FILLETS WITH AND WITHOUT SKIN.. The objective of this study was to evaluate the effect of different weights of Nile tilapia (Oreochromis niloticus) on yield and quality of smoked and in natura fillets, with and without skin. One hundred tilapias, divided into three weight classes $(\mathrm{C} 1=500-$ 600g; C2=601-700g; C3=701-800g) were used. Two fillet types, with skin and without skin were removed from each sample, salted and hot smoked. Weight affected yield of in natura $(\mathrm{C} 1=38.54 ; \mathrm{C} 2=40.23$ e $\mathrm{C} 3=40.47 \%)$ and smoked fillets $(\mathrm{C} 1=22.97 ; \mathrm{C} 2=24.51 \mathrm{e} C 3=$ $24.68 \%)$, and in natura fillet mass index $\left(\mathrm{C} 1=36.69 ; \mathrm{C} 2=39.45\right.$ e C3 $\left.=41.18 \mathrm{~g}^{-\mathrm{cm}^{-2}}\right)$. The latter was higher in classes $\mathrm{C} 2$ and $\mathrm{C} 3$. Fillet with skin had a higher $(\mathrm{p}<0.05)$ water activity $(0.99)$ rate than that of fillet without skin $(0.98)$. Salt rate was higher $(\mathrm{p}<0.01)$ in $\mathrm{smoked}$ fillets than in natura ones. It was observed higher salt levels in the $\mathrm{C} 1$ skinless class. With the exception of $\mathrm{a}^{*}$ and $\mathrm{b}^{*}$ in natura fillet, no difference was reported in color. Smoked fillets from C3 class fish were more acceptable by judges. In larger fish the equation Y= -21.52 $+0.16034 \mathrm{X}(\mathrm{r}=0.80)$, where $\mathrm{X}$ is the weight of fish, may be employed to calculate smoked fillets size, while $\mathrm{Y}=-17.74+0.14198 \mathrm{X}(\mathrm{r}=0.81)$ for smoked skin-less fillets. Regardless of skin presence, the smoked fillets from largest fishes (C2 and C3 classes) yielded better results (approximately 24\%), as well as in the sensorial analysis, related to salt ratio and general acceptance. Fillets in natura showed low values to $\mathrm{a}^{*}$ and $\mathrm{b}^{*}$. Weight classes and skin presence in the fillets had no influence in composition, but caused a variation in their area and thickness. The largest fillets were with skin, belonging to class C3.

Keywords: Nile tilapia (Oreochromis niloticus); fillet mass index; fillet area; sensorial analysis; proximate composition; smoking.

\section{1 - INTRODUÇÃO}

O crescimento significativo da aqüicultura brasileira, de 24.000 toneladas, em 1991, para 115.000 toneladas, em 1998 [31], despertou o interesse em relação à industrialização dessa produção. Dentre as espécies, a tilápia é considerada de grande importância na aqüicultura mundial, indicada para o cultivo intensivo, cuja produção está estimada em 1.500 .000 toneladas para 2010 [16].

1. Recebido para publicação em 04/04/2003. Aceito para publicação em 31/01/2005 (001087).

2. Depto de Zootecnia - Universidade Estadual de Maringá - Av. Colombo, 5790 - CEP87020-900. Maringá-PR.e.mail:mlrsouza@uem.br

${ }^{3}$ Depto de Zootecnia - FZEA/Universidade de São Paulo, Pirassununga -USP

${ }^{4}$ Universidade do Oeste Paulista - Unoeste. Presidente Prudente-SP. * A quem a correspondência deve ser enviada.
No Brasil, o processamento de peixes de água doce cultivados, em especial a tilápia do Nilo, tem sido direcionado principalmente ao congelamento. No entanto, outros processos devem ser propostos, como a defumação, que ao conferir características específicas ao produto, pode agregar-lhe valor. São necessárias para isso, investigações quanto à adequação do processamento em relação à matéria-prima e à qualidade do produto final $[1,28]$.

Peixes defumados estão entre os produtos que apresentam maior facilidade no preparo e utilização, podendo ser encontrados nos mercados em diversas formas. Os peixes de porte pequeno normalmente são defumados inteiros eviscerados e, os maiores, em filés, pedaços ou partes, borboleta ou espalmado, postas ou tronco limpo, sendo os cortes com ou sem pele [28, 43].

Dependendo da espécie de peixe não é possivel defumá-la sem a pele, principalmente àquelas com maior teor de lipídios, como o pacu (Piaractus mesopotamicus). 
ANDERSEN, THOMASSEN \& RØRA [2] afirmaram que elevados teores de lipídios proporcionam menor resistência dos filés ao trauma mecânico.

Em relação ao salmão do Atlântico (Salmo salar), RØRA et al. [38] observaram que, quanto maiores o teor de lipídios e o fator de condição, as perdas no processamento eram menores. O fator de condição, indice usado em estudos de biologia pesqueira, indica o grau de bem-estar do peixe, frente ao meio em que vive. Segundo BRAGA [10], o fator de condição é calculado pela relação entre peso e comprimento dos peixes, sendo útil para indicar o período de desova e alterações na densidade populacional e nas condições de alimentação das espécies.

Filés maiores, provenientes de peixes mais pesados, e com maior fator de condição, têm uma razão volume-superficie menor, que provavelmente auxilia a minimizar a desidratação, sendo essa, mais observada na superficie do filé. Peixes mais "gordos" apresentam maiores rendimentos comparados aos mais "magros", devido às menores perdas ocorridas durante a salga e defumação [41, 45, 47].

SOUZA et al. [47] observaram em tilápia do Nilo menores rendimentos em filés defumados com pele $(30,64 \%)$ e sem pele $(25,49 \%)$, quando comparados aos de pacu, mas tiveram melhor aceitação quanto aos atributos sensoriais.Variações nas percentagens de rendimento em filés in natura, em função de classes de peso, têm sido constatadas em tilápia vermelha [36] e tilápia do Nilo [46]. Todavia, avaliações de rendimentos em peixes, em função do processo tecnológico, são escassas na literatura.

O processo de defumação afeta de maneira parcial o valor nutricional do pescado [6, 18, 22, 26], pelas perdas de alguns aminoácidos e vitaminas [49]. Segundo OETTERER [30], o valor nutricional não é substancialmente reduzido. As mudanças aparentes na composição centesimal com base no peso úmido, normalmente, são devidas às perdas de umidade e acréscimo do sal durante a salmouragem [19, 35, 37, 47].

Objetivou-se com o presente estudo, avaliar o efeito de diferentes pesos de tilápia do Nilo sobre o rendimento e qualidade de seus filés submetidos à defumação, com e sem pele.

\section{2 - MATERIAL E MÉTODOS}

\section{1 - Preparação da amostra}

Foram utilizados 100 exemplares de tilápia do Nilo (Oreochromis niloticus), provenientes de tanques escavados de terra e submetidos à depuração, em tanques de alvenaria, com água corrente, por dois dias [42], para que posteriormente os filés não apresentassem eventuais problemas sensoriais ligados ao off-flavor. Os peixes, abatidos por choque térmico (imersão em água:gelo, 1:1, durante 20 minutos) e distribuídos em 3 classes de peso $(\mathrm{C} 1: 500$ a $600 \mathrm{~g}, \mathrm{C} 2=601$ a $700 \mathrm{~g}$ e $\mathrm{C} 3=701$ a $800 \mathrm{~g}$ ), foram lavados, descamados, eviscerados, deca- pitados, novamente lavados e filetados. A filetagem foi efetuada por uma única pessoa, que obteve filés com pele e sem pele, correspondentemente de cada exemplar. Os filés foram individualmente identificados, medidos e pesados antes da defumação.

\section{2 - Defumação}

A Figura 1 ilustra o processo de defumação a quente usado empregando um defumador industrial da marca Arprotec. O material comburente utilizado foi madeira, na forma de caibro ou bloco $(5 \times 90 \mathrm{~cm})$, produzindo a fumaça por fricção em uma polia de ferro. A fonte de calor para manutenção da temperatura desejada foi por meio de vapor proveniente de uma caldeira externa à unidade de beneficiamento interligada ao defumador por meio de tubulação.

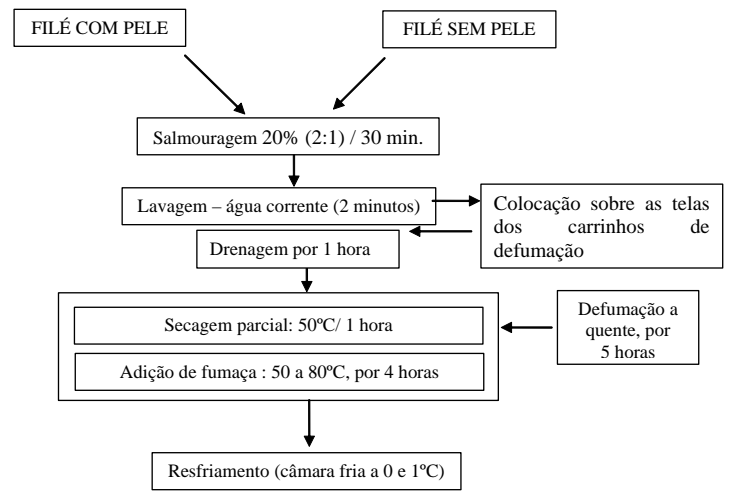

FIGURA 1. Fluxograma do processo de defumação a quente utilizado.

\section{3 - Rendimentos do processo e obtenção de da- dos biométricos dos filés in natura e defumados}

Para determinação dos rendimentos e perdas do processamento dos filés, o cálculo foi realizado em relação ao peso total do exemplar. A forma do filé foi calculada segundo MØRKØRE et al. [29]. O cálculo foi realizado como IMF (Índice de Massa de Filé) $=100 \mathrm{x}$ peso do filé $(\mathrm{g}) /(\text { comprimento do filé, em } \mathrm{cm})^{2}$.

Foram realizadas as medidas de comprimento do filé em relação à linha lateral do peixe, e a largura e espessura, em 3 pontos transversais ao comprimento do filé (aos 5, 8 e $11 \mathrm{~cm}$ ), conforme a Figura 2. Amostra foi colocada sobre folha de papel manteiga e contornada à lápis, e a determinação da área segundo um sistema de informações geográficas [4], com apoio do programa denominado Sistema de Processamento de Informações Geocodificadas - Spring [24], desenvolvido pelo Instituto Nacional de Pesquisas Espaciais.

\section{4 - Análises químicas}

Para as análises químicas realizadas em duplicatas ou triplicatas, a amostra foi antes mantida a $-18^{\circ} \mathrm{C}$. A umidade, cinzas, proteína e o cloreto de sódio foram quantificados segundo a AOAC [3] e os lipídios conforme BLIGH \& DYER [8]. 


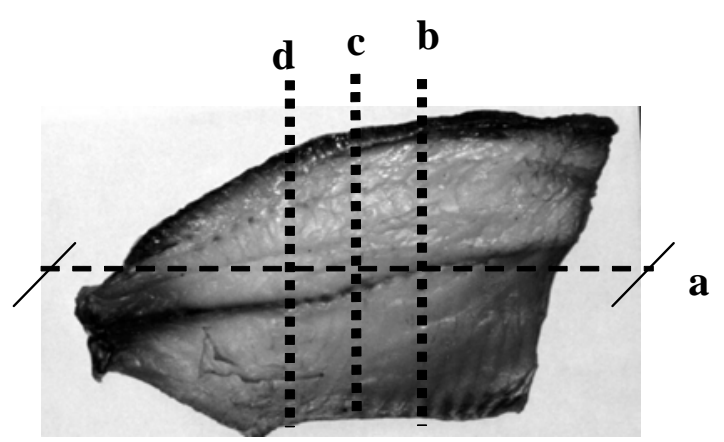

FIGURA 2. Pontos de medição do filé: para o comprimento (a), para a largura e espessura, as medidas foram tomadas em três pontos localizados a $5 \mathrm{~cm}$ (b), $8 \mathrm{~cm}$ (c) e $11 \mathrm{~cm}$ (d) transversalmente ao comprimento do filé.

\section{5 - Atividade de água $(\mathrm{Aw})$}

A atividade de água foi determinada por medida direta, em aparelho da marca Decagon Devices Inc., Modelo Aqualab Cx-2, segundo as instruções do fornecedor. As amostras foram trituradas e previamente condicionadas a $25^{\circ} \mathrm{C}$, por 30 minutos, e o aparelho calibrado com $\mathrm{NaCl} 6 \mathrm{M}(\mathrm{Aw}=0,76)$, a $25^{\circ} \mathrm{C}$.

\section{6 - Análise da cor}

A cor do filé foi determinada com auxílio de um colorímetro portátil (mod. MiniScan XE, marca Hunter Lab), com fonte de luz D65, ângulo de observação de $10^{\circ}$ e abertura da célula de medida de $30 \mathrm{~mm}$, com a escala $L^{*}, a^{*}, b^{*}$ do sistema CIELab [23]. A calibração do aparelho foi realizada conforme as instruções do fabricante.

\section{7 - Análise sensorial}

As amostras foram avaliadas por um painel de 30 provadores não-treinados. Vinte e quatro horas após a defumação, as amostras foram embaladas em folha de alumínio, aquecidas a $50^{\circ} \mathrm{C}$, por 2 minutos em forno convencional, e oferecidas aos provadores, que avaliaram os atributos sabor, textura, teor de sal e aceitação geral. Os filés inteiros foram embalados em bandejas de isopor e filme plástico e avaliados quanto à aparência, aroma, cor e aceitação geral. Foi utilizada uma ficha com escala hedônica de 9 pontos tendo, como extremos 1 (desgostei muitíssimo) e 9 (gostei muitíssimo) [14].

\section{8 - Delineamento experimental e análise estatís- tica}

O delineamento experimental foi inteiramente casualizado, num esquema fatorial $3 \times 2$ constituído de três classes de peso e presença ou ausência de pele no filé. Foram 33 repetições para a classe $1 \mathrm{com}$ pele, 32 para a classe 1 sem pele, 38 para a classe 2 com pele, 36 para classe 2 sem pele, 21 para a classe 3 com pele e 21 para a classe 3 sem pele, para analisar o rendimento do processamento, sendo considerado o filé a unidade experimental. Em relação ao teor de sal e cor foi acrescentado mais um fator ao modelo matemático, o tipo de matéria-prima (in natura e defumado), portanto um fatorial de $3 \times 2 \times 2$.

$\mathrm{Na}$ avaliação do Índice de Massa de Filé (IMF) foi usado um delineamento inteiramente casualizado com três tratamentos, sendo a classe de peso $(\mathrm{C} 1, \mathrm{C} 2$ e $\mathrm{C} 3)$ com o mesmo número de repetições utilizadas para o rendimento. O peixe inteiro foi considerado a unidade experimental.

Os dados foram submetidos à análise de variância, e as médias comparadas pelo teste de Tukey, ao nivel de 5\% de probabilidade [5]. Para análise sensorial foram utilizados os testes de Friedman (teste qui-quadrado) e o de Tukey não-paramétrico $( \pm=0,05)$ [51].

\section{3 - RESULTADOS E DISCUSSÃO}

\section{1 - Caracterização biométrica dos peixes}

Os peixes utilizados apresentaram pesos médios de $556,82,650,86$ e $731,16 \mathrm{~g}$, respectivamente para as classes 1 (500 a 600g), 2 (601 a 700g) e 3 (701 a 800g), cujo efeito foi observado em relação aos parâmetros biométricos considerados, exceção feita à percentagem de pele (Tabela 1). As percentagens de peles obtidas estão dentro da variação de 4,8 a $8,5 \%$ relatadas por MACEDO-VIEGAS, SOUZA \& KRONKA [25], Souza e MACEDO-VIEGAS [43] e SOUZA, MACEDO-VIEGAS \& KRONKA [44], para tilápia do Nilo.

O IMF foi superior $(\mathrm{P}<0,01)$ nos peixes das classes $3\left(41,18 \mathrm{~g} \cdot \mathrm{cm}^{-2}\right)$ e $2\left(39,45 \mathrm{~g} \cdot \mathrm{cm}^{-2}\right)$, comparado ao da classe $1\left(36,69 \mathrm{~g} \cdot \mathrm{cm}^{-2}\right)$ (Tabela 1). MØRKØRE et al. [29] encontraram valores de IMF entre 45,3 a $51,1 \mathrm{~g} . \mathrm{cm}^{-2}$ para filés de salmão, observando que, quanto maior o valor, menores as perdas ocorridas no processo de filetagem, fato constatado no presente estudo, conforme Tabelas 1 e 2 .

TABELA 1. Valores médios das características biométricas e dos indices de massa dos filés

\begin{tabular}{|c|c|c|c|c|c|c|c|c|}
\hline \multirow{2}{*}{ Fatores } & \multirow{2}{*}{$\begin{array}{l}\text { Peso total } \\
\text { (g) }\end{array}$} & \multicolumn{2}{|c|}{ Comprimento $(\mathrm{cm})$} & \multirow{2}{*}{$\begin{array}{l}\text { Altura } \\
(\mathrm{cm})\end{array}$} & \multirow{2}{*}{$\begin{array}{l}\text { Peso da } \\
\text { cabeça } \\
\text { (g) }\end{array}$} & \multirow{2}{*}{$\begin{array}{l}\text { Peso da } \\
\text { pele } \\
\text { (g) }\end{array}$} & \multirow{2}{*}{$\begin{array}{l}\text { Pele } \\
(\%)\end{array}$} & \multirow{2}{*}{$\begin{array}{l}\mathrm{IMF}^{1} \\
\left(\mathrm{~g} \cdot \mathrm{cm}^{-2}\right)\end{array}$} \\
\hline & & Total & Cabeça & & & & & \\
\hline \multicolumn{9}{|c|}{ Classe de peso (C) } \\
\hline C1 & $556,82 c^{2}$ & 30,87 c & $7,97 \mathrm{c}$ & $9,35 \mathrm{c}$ & $165,88 \mathrm{c}$ & $17,56 \mathrm{c}$ & $6,30 \mathrm{a}$ & $36,69 \mathrm{~b}$ \\
\hline C2 & 650,86 b & $32,41 \mathrm{~b}$ & $8,46 \mathrm{~b}$ & $9,82 \mathrm{~b}$ & $188,14 \mathrm{~b}$ & $21,58 \mathrm{~b}$ & 6,63 a & 39,45 a \\
\hline C3 & 731,16 a & 33,35 a & 8,76 a & 10,45 a & 209,31 a & 24,43 a & $6,71 \mathrm{a}$ & 41,18 a \\
\hline Teste F & $222,34^{* *}$ & $42,37 * *$ & $25,35 * *$ & $16,62 * *$ & $40,64^{* *}$ & $21,90^{* *}$ & $0,98 \mathrm{~ns}$ & $12,98^{* *}$ \\
\hline C.V. $(\%)^{3}$ & 4,79 & 3,18 & 22,22 & 7,05 & 9,53 & 18,68 & 18,57 & 8,58 \\
\hline
\end{tabular}

Não foi significativa a diferença para o IMF entre as classes de peso 2 e 3 (Tabela 1). Pode ser observado na Tabela 3, que os filés dessas duas classes apresentaram a mesma espessura aos 5 e $8 \mathrm{~cm}$ (que corresponde às maiores espessuras do filé), porém, a área foi significativamente superior para a classe 3 . Portanto, apesar dos filés da maior classe apresentarem maior área de superficie, continham espessura semelhante aos filés de peixes de peso inferior (C2), indicando que a 
diferença pode estar relacionada com a destreza operacional do filetador ou ao peixe (C3), por proporcionar um filé com menor massa muscular, observável na espessura do filé obtido a 5 e $8 \mathrm{~cm}$ em relação à linha lateral do peixe.

BOSWORTH, LIBEY \& NOTTER [9] e EINEN et al. [15] relataram que uma elevada massa corporal está relacionada com elevados rendimentos de filé, provavelmente devido à menor proporção da cabeça, ossos e nadadeiras nos peixes com uma forma corporal volumosa.

Para a defumação é interessante um filé de maior tamanho em área e em peso, conseqüentemente, com maior espessura, pois a desidratação ocorreria mais superficialmente durante o processo, não devendo ser excessiva para não afetar a textura do produto.

\section{2 - Rendimentos e perdas durante a filetagem e defumação}

$\mathrm{Na}$ Tabela 2 constam os pesos e rendimentos dos filés, in natura e defumados, e as perdas ocorridas com a filetagem e defumação. $\mathrm{O}$ peso do filé in natura e defumado variou em função da classe de peso e em relação à presença ou não da pele. Quanto aos rendimentos da filetagem, as classes $\mathrm{C} 2$ e $\mathrm{C} 3$ foram maiores, não diferindo entre si (C2=40,23\% e C3=40,47\%), assim como, em relação aos defumados (C2 = 24,51\%, C3 = 24,68\%). Os rendimentos dos filés in natura $(41,92 \%)$ e defumados $(25,17 \%)$ com pele, apresentaram-se superiores aos sem pele $(37,28$ e $22,72 \%$, respectivamente).

WEATHERLY \& GILL [50] estudando o efeito de classes de peso observaram maiores rendimentos de filé em truta arco-íris, para espécimes maiores. Todavia, segundo RASMUSSEN \& OSTENFELD [34], o rendimento de filé não é afetado pelo crescimento do peixe, mas a espécie pode ter efeito sobre essa variável, assim como, sobre o grau de mecanização, método de filetagem e destreza do filetador, conforme SOUZA [42], SOUZA \& MACEDO-VIEGAS [43] e SOUZA, MACEDO-VIEGAS \& KRONKA [44] e SOUZA et al. [46]

TABELA 2. Médias de rendimentos e perdas na filetagem e defumação

\begin{tabular}{|c|c|c|c|c|c|c|c|}
\hline \multirow[t]{2}{*}{ Fatores } & \multicolumn{2}{|c|}{ Peso do filé (g) } & \multicolumn{2}{|c|}{ Rendimento (\%) } & \multicolumn{3}{|c|}{ Perdas (\%) } \\
\hline & In natura & Defumado & In natura & Defumado & Filetagem & $\begin{array}{c}\text { No filé } \\
\text { defumado }\end{array}$ & $\begin{array}{c}\mathrm{Na} \\
\text { defumação }\end{array}$ \\
\hline \multicolumn{8}{|c|}{ Classes de peso (C) } \\
\hline C1 & $107,47 c^{1}$ & $64,01 \mathrm{c}$ & 38,54 b & $22,97 \mathrm{~b}$ & 61,46 a & 77,03 a & 15,57 a \\
\hline C2 & $129,77 \mathrm{~b}$ & $80,01 \mathrm{~b}$ & 40,23 a & 24,51 a & $59,77 \mathrm{~b}$ & $75,49 \mathrm{~b}$ & 15,72 a \\
\hline C3 & $146,91 \mathrm{a}$ & 90,26 a & 40,47 a & 24,68 a & $59,53 \mathrm{~b}$ & $75,32 \mathrm{~b}$ & 15,79 a \\
\hline \multicolumn{8}{|c|}{ Presença de pele no filé (P) } \\
\hline Com (FCP) & 131,64 a & 80,12 a & 41,92 a & 25,17 a & $58,08 \mathrm{~b}$ & $74,83 \mathrm{~b}$ & 16,75 a \\
\hline Sem (FSP) & $118,33 \mathrm{~b}$ & $72,22 \mathrm{~b}$ & $37,28 \mathrm{~b}$ & $22,72 \mathrm{~b}$ & 62,72 a & 77,28 a & $14,56 \mathrm{~b}$ \\
\hline \multicolumn{8}{|l|}{ Teste F } \\
\hline $\begin{array}{l}\text { Classe de } \\
\text { peso }(\mathrm{C})\end{array}$ & $230,92 * *$ & $108,60^{* *}$ & $12,55^{* *}$ & $7,13^{* *}$ & $12,55^{* *}$ & $7,13^{* *}$ & $0,14 \mathrm{~ns}$ \\
\hline $\begin{array}{l}\text { Presença } \\
\text { de pele(P) }\end{array}$ & $83,99 * *$ & $29,97 * *$ & $171,08^{* *}$ & $32,53^{* *}$ & $171,08^{* *}$ & $32,53^{* *}$ & $49,12 * *$ \\
\hline $\begin{array}{l}\text { Interação } \\
\text { C x P }\end{array}$ & $0,22 \mathrm{~ns}$ & $0,29 \mathrm{~ns}$ & $0,35 \mathrm{~ns}$ & $0,04 \mathrm{~ns}$ & $0,35 \mathrm{~ns}$ & $0,04 \mathrm{~ns}$ & $0,20 \mathrm{~ns}$ \\
\hline C.V. $(\%)^{2}$ & 7,36 & 11,92 & 5,63 & 11,23 & 3,70 & 3,54 & 12,59 \\
\hline
\end{tabular}

- Para cada fator analisado, classe de peso $(C)$ e presença de pele no filé $(P)$, médias na mesma coluna com a mesma letra não diferem significativamente pelo teste de Tukey (P>0,05);



Na literatura são encontrados rendimentos de filé sem pele de tilápia do Nilo variando de 25,4 a $42 \%$, em função do peso corporal, métodos de filetagem, comparação da forma de decapitação e remoção da pele e nadadeiras [13, 25, 42, 43, 45]. Em relação ao rendimento de produtos defumados, as percentagens variaram em relação a diversos fatores, tais como a técnica de defumação, espécie de peixe e forma de apresentação do produto.

SOUZA et al. [46] encontraram rendimentos de filé de tilápia do Nilo com pele de $27,11 \%$, com 4 horas de defumação a quente $\left(40^{\circ}\right.$ a $\left.90^{\circ} \mathrm{C}\right)$. Por outro lado, comparando a defumação a frio $\left(27-45^{\circ} \mathrm{C}\right.$, por 8 horas) e a quente $\left(60-80^{\circ} \mathrm{C}\right.$, por 4 horas) para filés de matrinxã com pele, SOUZA et al. [45] observaram rendimentos de 33,79 e 34,46\%, respectivamente.

O tipo de corte realizado no peixe para submetê-lo à defumação também influencia no rendimento. PEREIRA, SANT'ANA \& SANCHEZ [32] encontraram rendimentos na defumação de pacu (Piaractus mesopotamicus) em postas, de 39,3\%, e em "mariposa" ou "borboleta", de $38,6 \%$.

Considerando-se as perdas ocorridas durante o processo de filetagem e no produto final defumado, elas foram superiores para os peixes de menor peso (C1=61,46 e 77,03\%, respectivamente), comparados a C2 $(59,77$ e $75,49 \%$, respectivamente) e C3 $(59,53 \%$ e $75,32 \%$, respectivamente). Quanto às perdas ocorridas apenas durante o processo de defumação, não houve diferença significativa entre as classes de peso. As perdas no processamento de filetagem $(62,72 \%)$ e no filé defumado $(77,28 \%)$ foram superiores para os sem pele, entretanto, no período de defumação foram maiores para os filés com pele $(16,75 \%)$ (Tabela 2$)$.

As maiores perdas ocorridas nos filés com pele, durante o processo de defumação, podem estar associadas às perdas de água superficial, pela maior área de superficie destes filés, comparadas aos sem pele (Tabela 3), bem como, à maior quantidade de água que permanece na superficie da pele, embaixo das lamélulas de proteção e inserção da escama, decorrente da lavagem dos filés. RØRA et al. [38] afirmaram que a desidratação ocorre em maior grau na superficie do filé, favorecida pela maior relação superficie-volume do filé.

BERAQUET \& MORI [7] relataram perdas de peso na defumação a quente, de 20 a $27,5 \%$, para cavalinha "espalmada" (Scomber japonicus). Segundo SIGURGISLADOTTIR et al. [41], essas perdas podem variar de 10 a $25 \%$, de acordo com o tipo de filé in natura (espécie de peixe em função do teor de gordura), características do produto final e parâmetros usados no processo, tais como o tempo e temperatura. No presente trabalho as perdas ocorridas com a defumação estão dentro da faixa mencionada pelos autores citados.

A gordura também pode influenciar as perdas durante o processo de defumação. Peixes com maior teor perdem menos água. RØRA et al. [38] observaram que filés de salmão do Atlântico in natura, com 17,40\% de lipídios apresentaram perdas de peso de $8,1 \%$ quando 
defumados. As perdas de peso no processo de defumação, no presente estudo, variaram de 14,56 a 16,75\% entre os filés com e sem pele (Tabela 2), cujos níveis de lipídios estavam entre 1,41 a $1,79 \%$ (Tabela 4). Portanto, o aumento das perdas durante a defumação pode ser explicada também pela maior desidratação em peixes "magros" [41].

Por regressão linear foi constatada a existência de correlação significativa $(\mathrm{P}<0,01)$ entre o peso do peixe (X) e o peso do filé in natura (Y). Para a correlação do filé com pele a equação determinada foi $\mathrm{Y}=-19,09+0,23782 \mathrm{X}$ $(\mathrm{r}=0,92)$ e de sem pele $\mathrm{Y}=-15,70+0,21153 \mathrm{X}(\mathrm{r}=0,92)$. Também houve correlação entre o peso do peixe $(\mathrm{X})$ e filé defumado com pele $(\mathrm{Y}), \mathrm{Y}=-21,52+0,16034 \mathrm{X}(\mathrm{r}=0,80)$ e filé sem pele, $\mathrm{Y}=-17,74+0,14198 \mathrm{X}(\mathrm{r}=0,81)$. Da mesma forma, quando analisado o peso do filé in natura com o defumado com e sem pele, observou-se correlação, cujas equações foram $\mathrm{Y}=-7,84+0,68 \mathrm{X}(\mathrm{r}=0,92) \mathrm{e}$ $\mathrm{Y}=-6,52+0,69 \mathrm{X}(\mathrm{r}=0,92)$, respectivamente para os filés com pele e sem pele.

\section{3 - Caracterização do file in natura e defumado}

Com o aumento do peso dos peixes houve um incremento significativo em peso, espessura, comprimento, largura e, conseqüentemente, em área de filé, tanto in natura como defumado (Tabelas 2 e 3). Segundo CASTILLO CAMPO [11], o mercado americano tem preferência para filés de tilápias com 5 a 7 oz, ou 141 a 198g, e 7 a 9oz, ou 198 a 255g. De acordo com a Tabela 2 , os peixes da classe 3 atendem à essa exigência comercial.

Com o processo de defumação ocorreu redução na espessura, comprimento, largura e, conseqüentemente, na área dos filés referentes às três classes de peso, em comparação aos in natura. Os filés com pele apresentaram comprimento, largura, espessura (aos $11 \mathrm{~cm}$ ) e área superiores aos sem pele (Tabela 3).

TABELA 3. Valores médios de comprimento, largura, espessura e área dos filés defumados referentes às três classes de peso, comparados aos in natura.

\begin{tabular}{|c|c|c|c|c|c|c|c|c|}
\hline \multirow[t]{2}{*}{ Fatores } & \multirow{2}{*}{$\begin{array}{l}\text { Comp. } \\
\text { (cm) }\end{array}$} & \multicolumn{3}{|c|}{ Largura $(\mathrm{cm})$} & \multicolumn{3}{|c|}{ Espessura $(\mathrm{cm})$} & \multirow{2}{*}{$\begin{array}{l}\text { Área } \\
\left(\mathrm{cm}^{2}\right)\end{array}$} \\
\hline & & 5 & 8 & 11 & 5 & 8 & 11 & \\
\hline \multicolumn{9}{|c|}{ Classes de peso (C) } \\
\hline C1 & $16,40 c^{1}$ & $7,62 \mathrm{c}$ & $7,66 \mathrm{c}$ & $6,74 \mathrm{c}$ & $1,31 \mathrm{~b}$ & $1,22 \mathrm{~b}$ & $0,96 \mathrm{c}$ & $40,30 \mathrm{c}$ \\
\hline C2 & $17,59 \mathrm{~b}$ & $7,98 \mathrm{~b}$ & $8,21 \mathrm{~b}$ & $7,77 \mathrm{~b}$ & 1,48 a & $1,37 \mathrm{a}$ & $1,15 \mathrm{~b}$ & $47,55 \mathrm{~b}$ \\
\hline C3 & 18,18 a & 8,48 a & 8,59 a & 8,36 a & $1,50 \mathrm{a}$ & $1,43 \mathrm{a}$ & $1,24 \mathrm{a}$ & 51,73 a \\
\hline \multicolumn{9}{|c|}{ Presença de pele (P) } \\
\hline Com (FCP) & $17,91 \mathrm{a}$ & 8,38 a & 8,27 a & 7,85 a & 1,45 a & $1,36 \mathrm{a}$ & $1,14 \mathrm{a}$ & 48,58 a \\
\hline Sem (FSP) & $16,87 \mathrm{~b}$ & $7,68 \mathrm{~b}$ & 8,04 a & $7,40 \mathrm{~b}$ & $1,41 \mathrm{a}$ & $1,33 \mathrm{a}$ & $1,09 \mathrm{~b}$ & $44,47 \mathrm{~b}$ \\
\hline \multicolumn{9}{|c|}{ Forma de produto $(\mathrm{F})$} \\
\hline In natura & 18,03 a & 8,25 a & 8,49 a & 8,17 a & 1,59 a & $1,50 \mathrm{a}$ & $1,30 \mathrm{a}$ & 48,98 a \\
\hline Defumado & $16,75 \mathrm{~b}$ & $7,81 \mathrm{~b}$ & $7,82 \mathrm{~b}$ & $7,08 \mathrm{~b}$ & $1,27 \mathrm{~b}$ & $1,18 \mathrm{~b}$ & $0,93 \mathrm{~b}$ & $44,07 \mathrm{~b}$ \\
\hline \multicolumn{9}{|l|}{ Teste F } \\
\hline Classe (C) & $52,22 * *$ & $30,74 * *$ & $58,04^{* *}$ & $62,59 * *$ & $8,01^{* *}$ & $24,98^{* *}$ & $43,62 * *$ & $108,54 * *$ \\
\hline Pele (P) & $51,62 * *$ & $58,86 * *$ & $10,98^{* *}$ & $14,45^{* *}$ & $1,19 \mathrm{~ns}$ & $1,47 \mathrm{~ns}$ & $4,53 *$ & $41,13^{* *}$ \\
\hline Forma (F) & $78,12 * *$ & $24,29 * *$ & $89,89 * *$ & $82,90 * *$ & $56,04 * *$ & $160,11^{* *}$ & $221,78^{* *}$ & $58,68^{* *}$ \\
\hline $\begin{array}{l}\text { Interações } \\
\text { (CxP) }\end{array}$ & $0,31 \mathrm{~ns}$ & $0,37 \mathrm{~ns}$ & $0,02 \mathrm{~ns}$ & $1,65 \mathrm{~ns}$ & $1,03 \mathrm{~ns}$ & $0,18 \mathrm{~ns}$ & $0,11 \mathrm{~ns}$ & $2,31 \mathrm{~ns}$ \\
\hline$(\mathrm{CxF})$ & $0,07 \mathrm{~ns}$ & $2,20 \mathrm{~ns}$ & $0,04 \mathrm{~ns}$ & $0,39 \mathrm{~ns}$ & $0,44 \mathrm{~ns}$ & $1,91 \mathrm{~ns}$ & $1,90 \mathrm{~ns}$ & $0,63 \mathrm{~ns}$ \\
\hline (PxF) & $0,08 \mathrm{~ns}$ & 0,03 ns & $0,001 \mathrm{~ns}$ & $3,72 \mathrm{~ns}$ & $0,12 \mathrm{~ns}$ & $1,55 \mathrm{~ns}$ & $1,72 \mathrm{~ns}$ & $0,23 \mathrm{~ns}$ \\
\hline$(\mathrm{CxPxF})$ & $0,27 \mathrm{~ns}$ & $1,89 \mathrm{~ns}$ & $0,20 \mathrm{~ns}$ & $0,10 \mathrm{~ns}$ & $0,25 \mathrm{~ns}$ & $1,85 \mathrm{~ns}$ & $0,19 \mathrm{~ns}$ & $0,50 \mathrm{~ns}$ \\
\hline C.V. $(\%)^{2}$ & 5,58 & 7,52 & 5,88 & 10,47 & 19,64 & 12,41 & 15,08 & 8,12 \\
\hline
\end{tabular}

A perda observada deve-se principalmente à desidratação, que ocorre na superficie dos filés. Um filé maior, proveniente de um peixe de maior peso e com um elevado fator de condição, tem uma menor relação superficie-volume e, conseqüentemente, uma minimização na desidratação [38].

Houve correlação significativa $(\mathrm{P}<0,01)$ entre o peso do peixe $(\mathrm{X})$ e a área do filé com pele $(\mathrm{Y})$, expressada pela equação linear $\mathrm{Y}=12,014+0,062 \mathrm{X}(\mathrm{r}=0,85)$, e entre os filés sem pele $(\mathrm{Y}), \mathrm{Y}=10,083+0,057 \mathrm{X}(\mathrm{r}=0,80)$. O peso do filé in natura $(\mathrm{X})$ apresentou correlação positiva com a área do filé defumado com pele e sem pele (Y), $\mathrm{Y}=13,215+0,284 \mathrm{X}(\mathrm{r}=0,91)$ e $\mathrm{Y}=20,904+0,234 \mathrm{X}$ $(\mathrm{r}=0,78)$, respectivamente. A mesma correlação foi observada para o peso do filé defumado $(\mathrm{X})$ e a área do filé $(\mathrm{Y}), \mathrm{Y}=21,964+0,364 \mathrm{X}(\mathrm{r}=0,85)$.

\section{4 - Composição centesimal e teor de sal do filé in natura e defumado}

Pequena e insignificante variação foi observada na composição centesimal dos filés in natura, em função da classe de peso dos animais (Tabela 4). Pôde ser visto também que a classe de peso dos peixes e a presença ou não da pele não interferiram na composição centesimal dos filés defumados, conforme consta na Tabela 5.

TABELA 4. Médias dos valores da composição centesimal (\%) do filé in natura em função da classe de peso corporal.

\begin{tabular}{|c|c|c|c|c|}
\hline Tratamentos (classe de peso) & Umidade & Proteína & Lipídios & Cinzas \\
\hline $\mathrm{C} 1=500-600 \mathrm{~g}$ & $79,99 \mathrm{a}^{(1)}$ & $17,51 \mathrm{~b}$ & $1,41 \mathrm{a}$ & $1,09 \mathrm{a}$ \\
\hline $\mathrm{C} 2=601-700 \mathrm{~g}$ & $78,00 \mathrm{~b}$ & 19,31 a & $1,60 \mathrm{a}$ & 1,09 a \\
\hline $\mathrm{C} 3=701-800 \mathrm{~g}$ & $78,58 \mathrm{~b}$ & $18,55 \mathrm{ab}$ & $1,79 \mathrm{a}$ & $1,10 \mathrm{a}$ \\
\hline Teste F & $11,85^{* *}$ & $8,40 * *$ & $1,62 \mathrm{~ns}$ & $0,33 \mathrm{~ns}$ \\
\hline C.V. (\%) & 1,27 & 4,64 & 28,93 & 5,72 \\
\hline
\end{tabular}

O acréscimo de proteína, lipídios e cinzas, observados nos filés defumados (Tabela 5) em relação ao in natura (Tabela 4), é decorrente da desidratação muscular ocorrida, em função da defumação, de acordo com GONÇALVES \& PRENTICE-HERNÁNDEZ [19], RIBEIRO et al. [36] e SIGURGISLADOTTIR et al. [41]. O aumento nos teores de cinzas ocorreu também devido à incorporação de cloreto de sódio [20, 40].

TABELA 5. Composição centesimal (\%) do filé de tilápia defumado $^{1}$ com e sem pele

\begin{tabular}{lcccc}
\hline Fatores de variação & Umidade & Proteína & Lipídios & Cinzas \\
\hline Classes de peso (C) & & & & \\
C1 $=500-600 \mathrm{~g}$ & $61,00 \mathrm{a}^{2}$ & $30,37 \mathrm{a}$ & $3,51 \mathrm{a}$ & $5,25 \mathrm{a}$ \\
$\mathrm{C} 2=601-700 \mathrm{~g}$ & $61,68 \mathrm{a}$ & $29,32 \mathrm{a}$ & $3,69 \mathrm{a}$ & $5,31 \mathrm{a}$ \\
$\mathrm{C} 3=701-800 \mathrm{~g}$ & $61,60 \mathrm{a}$ & $29,52 \mathrm{a}$ & $3,49 \mathrm{a}$ & $5,30 \mathrm{a}$ \\
\hline Presença de pele no filé (P) & & & & \\
Com (FCP) & $61,19 \mathrm{a}$ & $29,90 \mathrm{a}$ & $3,49 \mathrm{a}$ & $5,42 \mathrm{a}$ \\
Sem (FSP) & $61,68 \mathrm{a}$ & $29,67 \mathrm{a}$ & $3,55 \mathrm{a}$ & $5,09 \mathrm{a}$ \\
\hline Teste F & & & & \\
Classe de peso (C) & $0,41 \mathrm{~ns}$ & $0,86 \mathrm{~ns}$ & $0,16 \mathrm{~ns}$ & $0,85 \mathrm{~ns}$ \\
Presença de pele (P) & $0,58 \mathrm{~ns}$ & $0,24 \mathrm{~ns}$ & $0,19 \mathrm{~ns}$ & $2,41 \mathrm{~ns}$ \\
Interação C x P & $0,64 \mathrm{~ns}$ & $0,55 \mathrm{~ns}$ & $0,35 \mathrm{~ns}$ & $0,69 \mathrm{~ns}$ \\
\hline C.V. (\%) & 2,73 & 6,29 & 22,22 & 10,07 \\
\hline
\end{tabular}

A pele, do filé defumado com pele, foi retirada antes das análises;

Para cada fator analisado, classe de peso (C) e presença de pele no filé (P), médias na mesma coluna com a mesma letra não diferem significativamente pelo teste de

Tukey $(\mathrm{P}>0,05)$. ns= não-significativo $(\mathrm{P}>0,05)$;
$3_{-}$Coeficiente de variação 
O teor de cloreto de sódio não foi influenciado pelas classes de peso dos peixes e presença ou não de pele no filé. Houve diferença significativa $(\mathrm{P}<0,01)$ para a forma de apresentação dos filés (in natura e defumado) como era esperado, e interação entre as classes de peso e presença ou não da pele (Figura 3).

O maior teor de sal $(3,16 \%)$ foi observado nos filés sem pele dos peixes da classe C1. Segundo TOMÉ, KODAIRA \& MATSUNAGA [48], filés de menor espessura $(1,91 \mathrm{~cm})$ apresentaram maior teor após a salmouragem de 30 minutos (3,57\%), comparados aos mais espessos $(3,58 \mathrm{~cm})(2,43 \%$ de sal). Os autores relataram que após a defumação o teor de sal foi de $7,84 \%$ e $3,15 \%$, respectivamente.

Não houve diferença significativa no teor de sal para os filés com pele, nas três classes de peso. Comparando a presença ou não da pele em relação às classes de peso, somente houve diferença para a C1 (Figura 3). Os filés da classe $\mathrm{C} 1$ (sem pele) absorveram mais sal provavelmente devido a sua menor espessura (Tabela 3) associada à ausência da pele, que atuaria como uma barreira. Segundo SHENDERYUK \& BYLOWSKI [39], a pele pode interferir no transporte de sal para o músculo e, conforme MOODY \& FLICK [28], a penetração do sal ocorre mais rapidamente nas áreas sem pele, com interferência da espessura.

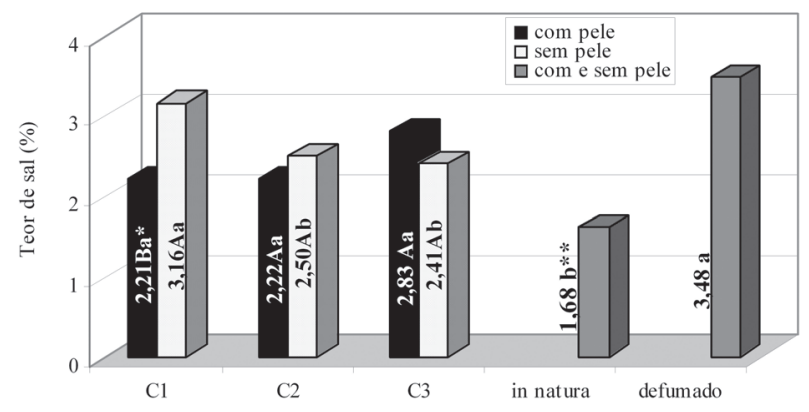

${ }^{*}$ ) As médias para presença ou não da pele dentro de cada classe de peso seguidas de mesma letra maiúscula não diferem pelo teste de Tukey $(\mathrm{P}>0,05)$. As médias para cada classe de peso em filés com ou sem pele seguidas de mesma letra minúsculas

não diferem pelo teste de Tukey $(\mathrm{P}>0,05)$.
$\left({ }^{* *}\right)$ Forma de processamento (in natura e defumado) com letras diferentes, dife rem entre si pelo teste de Tukey $(\mathrm{P}<0,05)$

FIGURA 3. Valores médios de cloreto de sódio nos filés in natura e defumados e filés com e sem pele, dentro de cada classes de peso ( $\mathrm{C} 1=500$ a $600 \mathrm{~g}, \mathrm{C} 2=601$ a $700 \mathrm{~g}$ e $\mathrm{C} 3=701$ a $800 \mathrm{~g})$.

Nos peixes que apresentam elevado teor de umidade e menor de gordura, ocorre um melhor intercâmbio de água-sal [48]. De acordo com MØRKØRE et al. [29], é possivel ajustar o método de salga com base no teor de gordura e tamanho do peixe, predizendo a concentração de sal no produto final. Da mesma forma, predizer a concentração de sal nos filés com e sem pele, a partir de seu tamanho (peso, área ou relação peso/área).

\section{5 - Atividade de água (Aw) do filé}

Os filés defumados $(\mathrm{Aw}=0,9)$ apresentaram Aw inferior $(\mathrm{P}<0,01)$ aos in natura $(\mathrm{Aw}=1,0)$, não havendo diferença significativa em função das classes de peso. Todavia, houve efeito $(\mathrm{P}<0,05)$ da presença da pele $(A w=0,99)$ nos filés em relação aos sem pele $(A w=0,98)$. A Aw é importante no desenvolvimento de reações químicas, bioquímicas e crescimento microbiológico [18]. Um produto cárneo com $\mathrm{Aw}>0,95$ e $\mathrm{pH}>5,2$, deve ser armazenado a uma temperatura $\mathrm{d} \leq \mathrm{a} 5^{\circ} \mathrm{C}$, sendo considerado de fácil deterioração.

\section{6 - Caracterização da cor do filé in natura e defu- mado}

Não foi observada variação $(P>0,05)$ de cor entre as amostras, considerando as classes de peso e presença ou não de pele no filé, indicando uniformidade de exposição à fumaça (Figura 4), fato confirmado na avaliação sensorial (Tabela б).

Os valores médios de croma $\mathrm{a}^{*} \mathrm{e} \mathrm{b}^{*}$ foram superiores $(\mathrm{P}<0,01)$ nos filés defumados em relação aos in natura, em função da exposição à ação da fumaça, mas, não houve efeito da classe de peso e da presença ou não de pele (Figura 4).

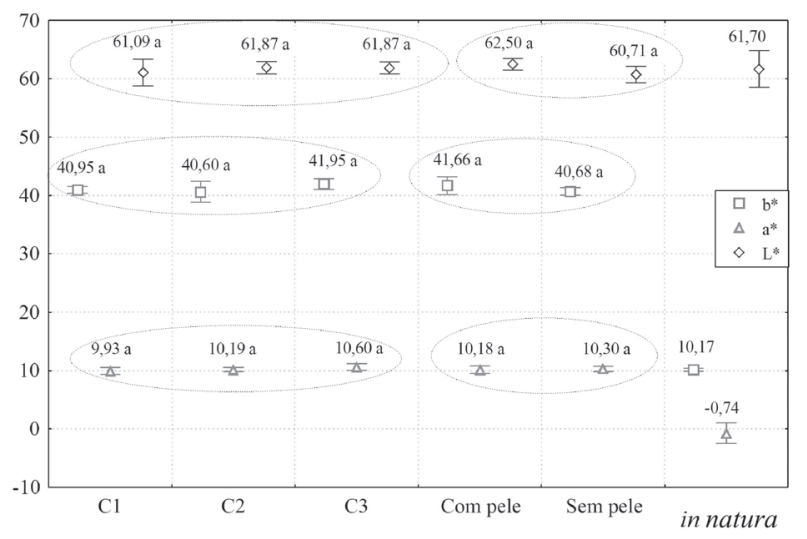

FIGURA 4. Luminosidade $L^{*}$ e a cromaticidade $a^{*} e b^{*}$ das amostras de filés defumados com e sem pele, provenientes de peixes das 3 classes de peso C1, C2 e C3. Os círculos representam grupos de médias estatisticamente semelhantes entre as classes de peso dos peixes ou entre os filés com presença ou não da pele $(\mathrm{P}>0,05)$. Os valores médios de $L^{*}$, a* e $b^{*}$ na mesma linha, para cada variável analisada, não diferem dos filés in natura.

BERAQUET \& MORI [7] afirmaram que o tempo de defumação contribuiu intensamente na formação da cor de peixes defumados. Também afirmou HASSAN [21], que o maior tempo de defumação resulta em filés mais escurecidos, devendo-se controlar a desidratação e cor dos filés para obtenção de maior aceitabilidade do produto final. De acordo com GILBERT \& KNOWLES [17] e PRÄNDL et al. [33], a cor é intensificada com a desidratação do produto e com o aumento do tempo de exposição, temperatura e oxigênio (influência no fluxo de fumaça).

A luminosidade $\left(L^{*}\right)$ não diferiu entre as classes de peso, presença ou não de pele, e filés in natura comparados aos defumados. Diferentemente ao observado na Figura 4, para luminosidade, CHOUBERT, BLANC \& 
COURVALIN [12] verificaram que esta diminui com a defumação, devido à deposição de componentes químicos produzidos pela pirólise da madeira. Por outro lado, segundo BERAQUET \& MORI [7] torna-se importante a elevação da temperatura (acima de $30^{\circ} \mathrm{C}$ ) no processo de defumação, para que a gordura do músculo aflore à superficie e melhore a aparência do produto, conferindo mais brilho. Dessa forma, gera um produto final com elevada luminosidade decorrente do alto brilho proporcionado pela liberação de gordura durante a defumação.

SHIAU \& CHAI [40] analisaram o cação Squalus acanthias defumado, apresentando a cor expressada por $\mathrm{L}=44,3, \mathrm{a}=7,0$ e $\mathrm{b}=11,5$, preferida pelos julgadores. Verificaram ainda que a cor do produto final foi afetada pelo tamanho do filé, teor de sal e quantidade de fumaça depositada.

\section{7 - Análise sensorial dos filés defumados intei- ros e em porções}

Não foram detectadas diferenças sensoriais nos filés defumados inteiros e em porções, em relação à aparência, aroma, cor, sabor e textura. Todavia, quanto ao teor de sal e aceitação geral, houve influência da classe de peso, sendo maior para os filés pertencentes aos peixes da C3 (Tabela 6).

Os filés com melhor aceitação apresentaram concentração de sal de 2,41 e 2,83\%, respectivamente para os sem e com pele (Tabela 6). Já, GONÇALVES \& PRENTICE-HERNÁNDEZ [20] relataram que a concentração mínima de cloreto de sódio que apresentou melhor aceitação para as anchovas foi de 3\%. Enquanto, os valores observados neste experimento foram inferiores aos relatados por estes autores.

TABELA 6. Valor da probabilidade para o teste qui-quadrado de Friedman e valores médios e teste de comparação múltipla não-paramétrica de Tukey $(\alpha=0,05)$ das notas atribuídas pelos provadores de filés defumados.

\begin{tabular}{|c|c|c|c|c|c|c|c|}
\hline \multirow[t]{2}{*}{ Fatores de variação } & \multicolumn{3}{|c|}{ Análise do filé inteiro } & \multicolumn{4}{|c|}{ Análise da porçào do filè } \\
\hline & Aparência & Aroma & Cor & Sabor & Textura & Sal & $\begin{array}{c}\text { Aceitação } \\
\text { geral }\end{array}$ \\
\hline Classe de peso (C) & 0,061 & 0,727 & 0,851 & 0,995 & 0,131 & 0,047 & 0,036 \\
\hline Presença de Pele $(\mathrm{P})$ & 0,149 & 0,735 & 0.583 & 0.203 & 0,188 & 0,567 & 0,382 \\
\hline Interação $(\mathrm{C} \times \mathrm{P})$ & 0,795 & 0,229 & 0,167 & 0,321 & 0,786 & 0,594 & 0,806 \\
\hline \multicolumn{8}{|l|}{ Classes de peso (C) } \\
\hline $\mathrm{Cl}$ & 6,25 & 6,32 & 6.45 & 7,10 & 7,23 & $7,13 \mathrm{~b}$ & $7.20 \mathrm{~b}$ \\
\hline $\mathrm{C} 2$ & 6,63 & 6,43 & 6,43 & 7,15 & 7,07 & $6,92 \mathrm{~b}$ & $6,93 \mathrm{~b}$ \\
\hline C3 & 6,53 & 6,43 & 6.55 & 7,12 & 7,43 & $7,22 \mathrm{a}$ & $7,28 \mathrm{a}$ \\
\hline \multicolumn{8}{|c|}{ Presença de pele no filé (P) } \\
\hline Com (FCP) & 6,61 & 6,46 & 6,54 & 7,04 & 7,11 & $6,94 \mathrm{a}$ & $7,08 \mathrm{a}$ \\
\hline Sem (FSP) & 6,63 & 6,33 & 6,41 & 7,20 & 7,38 & $7.23 \mathrm{a}$ & $7,20 \mathrm{a}$ \\
\hline
\end{tabular}

Segundo BERAQUET \& MORI [7], o tempo de exposição do filé à fumaça acentua o seu sabor, pela presença de compostos fenólicos, principalmente do 4 metilguaiacol [26, 27].

\section{4 - CONCLUSÕES}

Os filés de peixes das classes de peso C2 e C3 apresentaram melhores resultados em termos de rendimento, teor de sal e aceitação geral.
As classes de peso e a presença ou não de pele não influenciaram a composição centesimal dos filés defumados.

Não houve diferença na caracterização da cor do filé, exceto para $\mathrm{a}^{*} \mathrm{e} \mathrm{b}^{*}$, no in natura, que foi inferior.

As classes de peso e a presença ou não de pele causaram variações na espessura e área, conseqüentemente no comprimento e largura dos filés analisados. Os maiores filés foram os pertencentes à classe C3, com a pele. Com a defumação houve redução do tamanho (área e espessura) dos filés, quando comparados aos filés in natura.

Foi possivel predizer o tamanho do filé defumado, com ou sem pele, a partir do peso do peixe, assim como, de outras correlações de interesse industrial: peso do filé in natura, a partir do peso do peixe; e, peso do filé defumado, a partir do peso do filé in natura.

\section{5 - REFERÊNCIAS BIBLIOGRÁFICAS}

[1] AMERIO, M.; RUGGI, C.; BUDINI, C. Meat quality of reared fish nutritional aspects. Italian Journal Food Science, Pinerolo, v. 8, n. 3, p. 221-229, 1996.

[2] ANDERSEN, U. B.; THOMASSEN, M. S.; RØRA, A. M.B. Texture properties of farmed rainbow trout (Oncorhynchus mykiss): Effects of diet, muscle fat content and time of storage on ice. Journal of the Science Food Agriculture, Chichestes, v. 74, $\mathrm{n}^{\circ} .3$, p. 347-353, 1997.

[3] AOAC. ASSOCIATION OF OFFICIAL ANALYTICAL CHEMISTS. Oficial methods of analysis. Arlington, 1995. v. 2, cap. 35, p.1-30.

[4] ASSunÇÃO, G. V.; FORMAgGio, A. R.; AlVES, A. R. Mapa de aptidão agrícola das terras e uso adequado das terras: uma abordagem usando SGI e imagens de satélite. In: SIMPÓSIO BRASILEIRO DE SENSORIAMENTO REMOTO, 4., Manaus, 1990, Anais... São José dos Campos: INPE, 1990. p.162 - 166.

[5] BANZATTO, D. A.; KRONKA, S. N. Experimentação agricola. 3. ed. Jaboticabal: FUNEP, 1995.

[6] BELTRAN, A.; MORAL, A. Changes in fatty acid composition of fresh and frozen sardine (Sardina pilchardus W.) during smoking. Food Chemistry, Barking, v. 42, p. 99-109, 1991.

[7] BERAQUET, N. J.; MORI, E. E. M. Influência de diferentes métodos de defumação na aceitabilidade de cavalinha Scomber japonicus Houtt defumada. Coletânea do ITAL, Campinas, v.14, p.1-25, 1984.

[8] BLIGH, E. G.; DYER, W. J. A rapid method of total lipid extraction and purification. Canadian Journal of Biochemistry and Physiology, Ottawa, v. $37, \mathrm{n}^{\circ} .8$, p. 911-917, 1959.

[9] BOsworth, B.G.; LIBEY, G. S.; NOTTER, D. R. Relatonships among total weight, body shape, visceral components, and fillet traits in Palmetto Bass (Striped Bass Female Morone sascatilis x White Bass male $M$. chrysops) and Paradise Bass (Striped Bass Female $M$. saxatilis x Yellow Bass $M$. minissippiensis). Journal of the World Aquaculture Society, Baton Rouge, v. 29, $\mathrm{n}^{\circ} .1$, p. 40-50, 1998.

[10] BRAGA, F. M. S. Estudo entre fatores de condição e relação peso/comprimento para alguns peixes marinhos. Revista Brasileira de Biologia, Rio de Janeiro, 
v. 46, n. 2, p. 339-346, 1986.

[11] CASTillo CAMPO, L. F. Situación del comércio de tilápia: en el año 2000. Panorama Acuícola, Obregón, v. 6, n. 3, p. 24-27, 2001.

[12] ChOUBERT, G.; BlanC, J.M.; COURVAlin, C. Muscle carotenoid content and colour of farmed rainbow trout fed astaxanthin or canthaxanthin as affected by cooking and smoke-curing procedures. International Journal of Food Science and Technology, Oxford, v. 27, n. 3, p. 277-284, 1992.

[13] CLEMENT, S.; LOVELL, R. T. Comparison of culture Nile tilapia (Oreochromis niloticus) and channel catfish (Ictalurus punctatus). Aquaculture, Amsterdan, v.119, p. 299-310, 1994.

[14] DUTCOSKY, S. D. Análise sensorial de alimentos. Curitiba: Champagnat, 1996.

[15] EINEN, O.; MORKORE, T.; RORA, A. M. B.; THOMASSEN, M. S. Feed ration prior slaughter potential tool for managing product quality of Atlantic salmon (Salmo salar). Aquaculture, Amsterdan, v. 78, n. 2, p. 149-169, 1999.

[16] FITZSIMMONS, K. Tilapia: the most important aquaculture species of the $21^{\text {st }}$ century. In: INTERNACIONAL SYMPOSIUM ON TILAPIA AQUACULTURE, 5., 2000, Rio de Janeiro. Proceedings... Rio de Janeiro: DPA/MA, 2000. p. 3-8.

[17] GILBERT, J.; KNOWLES, M.E. The chemistry of smoked foods: a rewiew. Journal of Food Technology, v. 10, p. 245-261, 1975.

[18] GIRARD, J. P. Ahumado. In: GIRARD, J. L (Ed.). Tecnologia de la carne y de los productos cárnicos. Zaragoza: Acribia, 1991. p.183-229.

[19] GOnÇAlves, A. A.; PREnTICE-HERnÁndeZ, C. Defumação líquida de anchova (Pomatomus saltatrix): Efeito do processamento nas propriedades químicas e microbiológicas. Ciênc. Tecnol. Aliment., Campinas, São Paulo, v. 18, n. 4, p. 438-443, 1998.

[20] GONÇALVES, A. A.; PRENTICE-HERNÁNDEZ, C. Defumação liquida de anchova (Pomatomus saltatrix): estabilidade lipídica durante o processamento e o armazenamento. Revista Instituto Adolfo Lutz, São Paulo, v. 58, n. 1, p. 69-78, 1999.

[21] HASSAN, I. M. Processing of smoked common carp fish and its relation to some chemical, physical and organoleptic properties. Food Chemistry, Barking, v. 27, p. 95-106, 1988.

[22] HAARD, N. F. Review: control of composition and food quality attributes of cultured fish. Food Research International, New York, v. 25, n. 4, p. 289-307, 1992.

[23] HUNTER, R.S. The measurement of appearance. New York: John Wiley \& Sons, 1975.

[24] INPE. Instituto Nacional de Pesquisas Espaciais. Apostila do curso Spring 3.3: Spring básico. São José dos Campos, 1999. Apostila.

[25] MACEDO-VIEGAS, E. M.; SOUZA, M. L. R.; KRONKA, S. N. Estudo da carcaça de tilápia do Nilo (Oreochromis niloticus), em quatro categorias de peso. Revista Unimar, Maringá, v.19, n. 3, p. 863-870, 1997.

[26] MAGA, J. A.The flavor chemistry of wood smoke. Food Reviews International, New York, v. 3, $\mathrm{n}^{\circ}$. 1-2, p.139183, 1987.

[27] MAGA, J. A smoke in food processing. Colorado, Florida: CRC Press, 1988.

[28] MOODY, M.W.; FLICK, G. J. Smoked, cured, and dried fish. In: MARTIN, R. E.; FLICK, G. J. (Ed.). The sea food industry. New York: Van Nostrand Reinhold, 1990. cap. 22, p. 381-406.

[29] MØRKØRE, T.; VALLET, J. L.; CARDINAL, M.; GOMEZGUILLEN, M.C.; MONTEIRO, P.; TORRISSEN, O. J.; NORTVEDT, R.; SIGURGISLADOTTIR, S.; THOMASSEN, M. S. Fat content and fillet shape of Atlantic salmon: relevance for processing yield and quality of raw and smoked products. Food Engineering and Physical Properties, [S.1], v. 66, n. 9, p.13481354, 2001.

[30] OETTERER, M. 2002. Industrialização do pescado cultivado. Guaíba: Agropecuária, 2002.

[31] OSTRENSKY, A.; BORGHETTI, J. R.; PEDINI, M.. Situação atual da aqüicultura brasileira e mundial. In: VALENTI, W.C.; POLI, C.R.; PEREIRA, J. A.; BORGHETTI, J. R. (Ed.). Aqüicultura no Brasil: bases para um desenvolvimento sustentável. Brasília, DF: MCT: CNPq, 2000. cap.12. p. 353-381.

[32] PEREIRA, E.F.; SANT'ANA, L.S.; SANCHEZ, L. Influência dos diferentes tipos de cortes na aparência do pacu (Piaractus mesopotamicus) defumado. In: JORNADA CIENTÍFICA DA ASSOCIAÇÃO DOS DOCENTES DOS CAMPUS DE BOTUCATU, 8.,1993, Botucatu. Anais...Botucatu: Unesp, 1993.

[33] PRÄNDL, O.; FISCHER, A.; SCHMIDHOFER, T.; SINELL, H. J. Tecnologia e higiene de la carne. Zaragoza: Acribia, 1994. 854 p.

[34] RASMUSSEN, R. S.; OSTENFELD, T. H. Effect of growth rate on quality traits and feed utilization of rainbow trout (Oncorhyncus mykiss) and brook trout (Salvelinus fontinalis). Aquaculture, Amsterdan, v.184, p. 327-337, 2000.

[35] RIBEIRO, S. C. A. Secagem e defumação liquida de filé de peixe matrinchã (Brycon cephalus). Campinas, SP, 2000. 101p. Dissertação (Mestrado em Engenharia de Alimentos)-Faculdade de Engenharia de Alimentos, Universidade Estadual de Campinas.

[36] RIBEIRO, L. P.; LIMA, L. C.; TURRA, E. M.; QUEIROZ, B. M.; RIBEIRO, T. G.; MIRANDA, M.O.T. Efeito do peso e da destreza do operador sobre o rendimento de filé em "tilápia-vermelha" Oreochromis spp. In: AQUICULTURA BRASIL'98, 1998, Recife. Anais/ Proceedings... Recife: Abraq, 1998. p. 322.

[37] ROBB, D. H. F.; KESTIN, S. C; WARRISS. P. D.; NUTE, G. R. Muscle lipid content determines the eating quality of smoked and cooked Atlantic salmon (Salmo salar). Aquaculture, Amsterdan, v. 205, p. 345-358, 2002.

[38] RØRA, A. M.B.; KVALE, A.; MØRKØRE, T.; RORVIK, K.; STEIEN, S. H.; THOMASSEN, M. S. Process yield, colour and sensory quality of smoked Atlantic salmon (Salmo salar) in relation to raw material characteristics. Food Research International, New York, v. 31, $\mathrm{n}^{\circ} .8$, p. 601-609, 1998.

[39] SHENDERYUK, V. I.; BYLOWSKI, P. J. Salazón y escabechado del pescado. In: SIKORSKI, Z.E. (Ed.). Tecnologia de los productos del mar: recursos, composição nutritiva y conservation. Zaragoza: Editorial Acribia, 1990. cap. 9, p. 199-219.

[40] SHIAU, C.Y.; CHAI, T. Smoked dogfish processing and its refrigerated storage stability. Journal of Food Science, Chicago, v. 50, nº. 5, p. 1348-1350, 1985.

[41] SIGURGISLADOTTIR, S.; SIGURDARDOTTIR, M. S.; TORRISSEN, O.; VALLET, J. C.; HAFSTEINSSON, H. Effects of different salting and smoking processes on the microstructure, the texture and yield of Atlantic salmon (Salmo salar) fillets. Food Research International, Essex, n. 33, p. 847-855, 2000. 
[42] SOUZA, M. L. R. Industrialização, comercialização e perspectivas. In: MOREIRA, H. L.M.; VARGAS, L.; RIBEIRO, R. P.; ZIMMERMANN, S. (Ed.). Fundamentos da moderna aqüicultura. Canoas: ULBRA, 2001. p.149189 ,

[43] SOUZA, M. L. R.; MACEDO-VIEGAS, E. M. Comparação de quatro métodos de filetagem utilizado para a tilápia do Nilo (Oreochromis niloticus) sobre o rendimento do processamento. Infopesca International, Uruguay, $\mathrm{n}$. 7, p. 26-31, 2001.

[44] SOUZA, M. L. R.; MACEDO-VIEGAS, E. M.; KRONKA, $\mathrm{S}$. N. Influência do método de filetagem e categorias de peso sobre rendimento de carcaça, filé e pele da tilápia do Nilo (Oreochromis niloticus). Revista Brasileira de Zootecnia,Viçosa, v. 28, n. 1, p.1-6, 1999.

[45] SOUZA, M. L. R.; MACEDO-VIEGAS, E. M.; CARNEIRO, D. J.; ASSANO, M.; VIDOTTI, R. M.; KRONKA, S. N. 2000. Comparação dos processos de defumação a frio e a quente em filés de matrinxã (Brycon cephalus) sobre o rendimento e características organolépticas. In: AQÜICULTURA BRASIL, 2000, Florianópolis. Anais/ Proceedings...Florianópolis: Abraq, 2000. 1CD-ROM.

[46] SOUZA, M. L. R.; MARENGONI, N. G.; PINTO, A. A.; CAÇADOR, W. C. Rendimento do processamento da tilápia-do-nilo (Oreochromis niloticus): tipos de corte de cabeça em duas categorias de peso. Acta Scientiarum, Maringá, v. 22, n. 3, p. 701-706, 2000.

[47] SOUZA, M. L. R.; MACEDO-VIEGAS, E. M.; FARIA, R. H. S.; POVH, J. A.; GANECO, L. N.; KIRSCHNIK,
WAGNER, P. M. Análise quantitativa do processo de defumação e avaliação sensorial de filés de tilápia do Nilo (Oreochromis niloticus) e pacu (Piaractus mesopotamicus). In: AQÜICULTURA BRASIL, 2002. Goiânia. Anais... Goiânia: Abraq, 2002. p.228.

[48] TOMÉ, E.; KODAIRA, M.; MATSUNAGA, Y. Efect de las condiciones de procesamiento, contenido de grasa y grado de frescura de la matéria prima em la calidad de filetes de bagre ahumados. Food Science and Technology International, Oxford, v. 5, n. 2, p.167176, 1999.

[49] VISHWANATH, W.; LILABATI, H.; BIJEN, M. Biochemical, nutricional and microbiological quality of fresh and smoked mud eel fish Monopterus albus: comparative study. Food Chemistry, Barking, v. 61, $\mathrm{n}^{\circ} .1 / 2$, p. 153-156, 1998.

[50] WEATHERLY, A. H.; GILL, H. S. Relative growth of tissues at different somatic growth rates in rainbow trout Salmo Gairdneri Richardson. Journal of Fish Biology, London, v. 22, p. 43-60, 1983.

[51] ZAR, J. H. Biostatistical analysis. $4^{\text {th }}$ ed. New Jersey: Prentice Hall, 1999.

\section{6 - AGRADECIMENTOS}

À CAPES, pela bolsa concedida, e à Ana Mônica Q. Barbosa Habitante, Profa. Dra. Regina Barbieri Carva1ho, Tânia, Felipe Aiura, Ana Eliza Baccarin e Prof. Dr. Marcos Rafael Nanni, pela colaboração recebida. 